\section{RM Schek \\ JM Taboas \\ SJ Hollister \\ PH Krebsbach}

\title{
Tissue engineering osteochondral implants for temporomandibular joint repair
}

Authors' affiliations:

R.M. Schek, J.M. Taboas, S.J. Hollister, P.H. Krebsbach, Department of Biomedical Engineering, University of Michigan, Ann Arbor, MI, USA

R.M. Schek, J.M. Taboas, P.H. Krebsbach, Department of Biologic and Materials Sciences, School of Dentistry, University of Michigan, Ann Arbor, MI, USA

S.J. Hollister, Department of Mechanical Engineering and Department of Surgery, University of Michigan, Ann Arbor, MI, USA

\section{Correspondence to:}

Paul H. Krebsbach

1011 N University Ave.

Ann Arbor

MI 48109

USA

Tel.: +1 7349362600

Fax: +1 7347633453

E-mail:paulk@umich.edu
Dates:

Accepted 10 August 2005

To cite this article:

Orthod Craniofacial Res 8, 2005; 313-319

Schek RM, Taboas JM, Hollister SJ, Krebsbach PH: Tissue engineering osteochondral implants for temporomandibular joint repair

Copyright $\odot$ Blackwell Munksgaard 2005

\begin{abstract}
Authors - Schek RM, Taboas JM, Hollister SJ, Krebsbach PH Tissue engineering has provided an alternative to traditional strategies to repair and regenerate temporomandibular joints (TMJ). A successful strategy to engineer osteochondral tissue, such as that found in the TMJ, will produce tissue that is both biologically and mechanically functional. Image-based design (IBD) and solid free-form (SFF) fabrication can be used to generate scaffolds that are load bearing and match patient and defect site geometry. The objective of this study was to demonstrate how scaffold design, materials, and biological factors can be used in an integrated approach to regenerate a multi-tissue interface. IBD and SFF were first used to create biomimetic scaffolds with appropriate bulk geometry and microarchitecture. Biphasic composite scaffolds were then manufactured with the same techniques and used to simultaneously generate bone and cartilage in discrete regions and provide for the development of a stable interface between cartilage and subchondral bone. Poly-L-lactic acid/ hydroxyapatite composite scaffolds were differentially seeded with fibroblasts transduced with an adenovirus expressing bone morphogenetic protein-7 in the ceramic phase and fully differentiated chondrocytes in the polymeric phase, and were subcutaneously implanted into mice. Following implantation in the ectopic site, the biphasic scaffolds promoted the simultaneous growth of bone, cartilage, and a mineralized interface tissue. Within the ceramic phase, the pockets of tissue generated included blood vessels, marrow stroma, and adipose tissue. This combination of IBD and SFF-fabricated biphasic scaffolds with gene and cell therapy is a promising approach to regenerate osteochondral defects and, ultimately, the TMJ.
\end{abstract}

Key words: biomaterials; bone; cartilage; temporomandibular joint; tissue engineering 


\section{Introduction}

In response to the significant need to reconstruct the temporomandibular joint (TMJ), autogenous tissue grafting and alloplastic materials are regularly employed (1-3). Neither therapy is ideal, however, because allografts are associated with donor site morbidity and are poorly shaped for placement in TMJ defects, and alloplastics do not respond to normal biochemical or mechanical signals $(4,5)$. Tissue engineering approaches have the potential to overcome the lack of donor tissue and create a TMJ replacement that is both biologically and mechanically functional. Engineering of such a graft will require the production of both bone and fibrocartilage. Strides have been made in tissue engineering of these tissues separately (6-13), but a combined approach to generate both bone and cartilage simultaneously will likely be required to regenerate an articulating osteochondral joint. We propose the use of a designed biphasic scaffold to guide the growth of these two different tissues into a single implant.

Biphasic scaffolds contain discrete regions that are optimized for selective growth of the desired tissue by utilizing different material types, material properties, internal architectures (e.g. porosity, pore interconnectivity), cells, and biological factors. Such scaffolds have previously been investigated for ostochondral regeneration (14-16). Taken together, these studies demonstrated the ability of biphasic scaffolds to support cell growth and differentiation into bone and cartilage. The scaffolds used in these studies did not control the scaffold internal architecture, which may enhance osteochondral tissue regeneration. Control over the biphasic scaffold internal pore architecture may be used to create scaffolds with mechanical and biological properties that provide immediate mechanical function while promoting tissue ingrowth $(17,18)$. Similarly, control over the exterior shape of the scaffold may be used to match the scaffold geometry with a temporomandibular defect site or the contours of the articular surface. To create a scaffold with complex internal structures and correctly matched anatomic shape while providing for rapid and flexible manufacturing, computational design and solid free-form (SFF) fabrication techniques may be needed.

Solid free-form fabrication is a highly flexible manufacturing technique in which scaffolds are built in a layer-by-layer fashion from computer-generated design files. When image-based design (IBD) is employed, these computationally designed files are matched to magnetic resonance imaging (MRI) or computer tomographic (CT) data of the patient defect site (19). Additionally, the microstructure of these designed scaffolds can be optimized to allow both mechanical function and tissue invasion $(20,21)$. This flexible design and manufacturing platform can also be used to manufacture biphasic scaffolds in which discrete regions are optimized for the growth of specific tissue types. Already, SFF has been used to create biphasic scaffolds that allow for selective seeding and the growth of tissues in the appropriate phases $(22,23)$.

Scaffolds produced via SFF fabrication would have numerous advantages but must be combined with a biological factor to trigger tissue formation; we propose gene therapy to serve this role. Ex vivo gene therapy, in which cells are isolated, transduced in vitro, and then implanted into the host, was chosen for this work. This is because regeneration of large defects, such as the TMJ, may require seeding the designed scaffolds with cells in order to provide a cell pool for tissue regeneration. In this study, we aimed to initiate the formation of bone using fibroblasts virally transduced to express bone morphogenetic protein-7 (BMP-7) and the formation of cartilage using primary chondrocytes.

We hypothesized that designed biphasic scaffolds, in conjunction with ex vivo gene therapy and specific progenitor cells, are excellent candidates for the engineering of TMJ. Here we have demonstrated how IBD and SFF can be used to design scaffolds that match articulating surface geometry and manufactured from materials that may allow bearing of functional loads while promoting regeneration. We then investigated the generation of osteochondral tissue when bone and cartilage progenitor cells were simultaneously cultured in discrete regions of the scaffolds in a subcutaneous murine model.

\section{Methods}

\section{Scaffold design and manufacture}

The scaffold shape and internal pore architecture can be defined using the IBD method previously described (19). In this method, an image of the joint to be reconstructed is obtained by MRI and/or CT. The tissue replacement area is then defined by image processing 
and digitization; this creates the external scaffold design. The heterogeneous internal scaffold architecture designs can then be created and optimized as separate image databases. The porous architecture can be created either using geometric primitive shapes like cylinders or spheres (16), or using microstructure topology optimization methods (17). The external scaffold design database is then combined with the architecture databases to create the final complete scaffold design as an image database. The internal scaffold design can then be designed and optimized. Finally, the entire scaffold design is then translated from image data to stl. or a similar format for manufacture using SFF fabrication. Using this procedure, a biomimetic scaffold, containing an orthogonal porous region was designed and fabricated from a single polymeric material via SFF (Fig. 1).

Scaffolds with a simpler geometry were used for in vivo evaluation of how scaffold design and material properties effected tissue formation. These composite scaffolds were composed of two bonded cylinders, one hydroxyapatite (HA) and one poly-L-lactic acid [PLA, $\mathrm{MW}_{\text {(weight avg) }}=147$ 000; Birmingham Polymers, Inc., Birmingham, AL, USA], each $5 \mathrm{~mm}$ in diameter and $3 \mathrm{~mm}$ in height. The HA phase contained either $300 \mu \mathrm{m}$ diameter orthogonal pores with a porosity of $50 \%$. These were manufactured using indirect SFF fabrication as previously described (24). Briefly, the computerdesigned molds were created on a Model Maker II (SolidScape, Inc., Merrimack, NH, USA) wax inkjet printer and an HA/acrylic slurry was cast into the molds and sintered (25). The polymer sponges were created using a salt leaching technique as described previously (24). Sieved $\mathrm{NaCl}(100-120 \mu \mathrm{m}$ diameter; Sigma, St Louis, MO, USA) were packed into $5 \mathrm{~mm}$ diameter by $3 \mathrm{~mm}$ high molds and $70 \mu \mathrm{l}$ of $7.5 \% \mathrm{w} / \mathrm{v}$
PLA in methylene chloride (Sigma) were cast into the molds. Finally, the solvent was evaporated and the salt porogen removed by soaking water for $48 \mathrm{~h}$.

The two phases of the scaffold were assembled prior to cell seeding and implantation as shown in Fig. 2. Completed scaffolds were allowed to dry overnight and sterilized by soaking in $70 \%$ ethanol for $24 \mathrm{~h}$.

\section{Seeding and implantation of scaffolds}

The biphasic scaffolds were seeded with chondrocytes in the polymeric phase and transduced fibroblasts in the ceramic phase to trigger the growth of cartilage and bone, respectively. Articular cartilage was harvested from domestic pig knee joints and the chondrocytes were isolated by agitating the tissue overnight in 1.5 $\mathrm{mg} / \mathrm{ml}$ collagenase II (Sigma) in $\alpha$-minimum essential medium ( $\alpha$-MEM). The chondrocytes were resuspended in culture medium [CM, $\alpha$-MEM with $10 \%$ FBS and $1 \%$ penicillin/streptomycin (Gibco, GIBCO Invitrogen, San Diego, CA, USA)], and plated in tissue culture flasks (BD Biosciences, Lexington, KY, USA). After 24 h, adherent cells were used for cell seeding. Primary human gingival fibroblasts (HGFs) were prepared from discarded tissue following oral surgery in compliance with the University of Michigan Institutional Review Board. Cells migrating from diced tissue onto tissue culture polystyrene were isolated and expanded in CM (26). Passage 4 fibroblasts were infected with AdCMV-BMP-7, a recombinant adenovirus construct expressing the murine BMP-7 gene under a cytomegalovirus (CMV) promoter (27). Infections were performed overnight with 1000 plaque forming units per cell. Such infected primary cells have been shown to form bone in vivo (28-31).

Transduced HGFs were suspended in $50 \mathrm{mg} / \mathrm{ml}$ bovine plasma-derived fibrinogen in $\alpha$-MEM (Sigma).
Fig. 1. Image-based design allowing creation of defect site-specific scaffolds. The patient image (A) is used in conjunction with appropriate microstructure architecture to create the design for the implant (B). This design can then be produced using solid free-form fabrication, as in this prototype constructed from a single polymeric material (C).
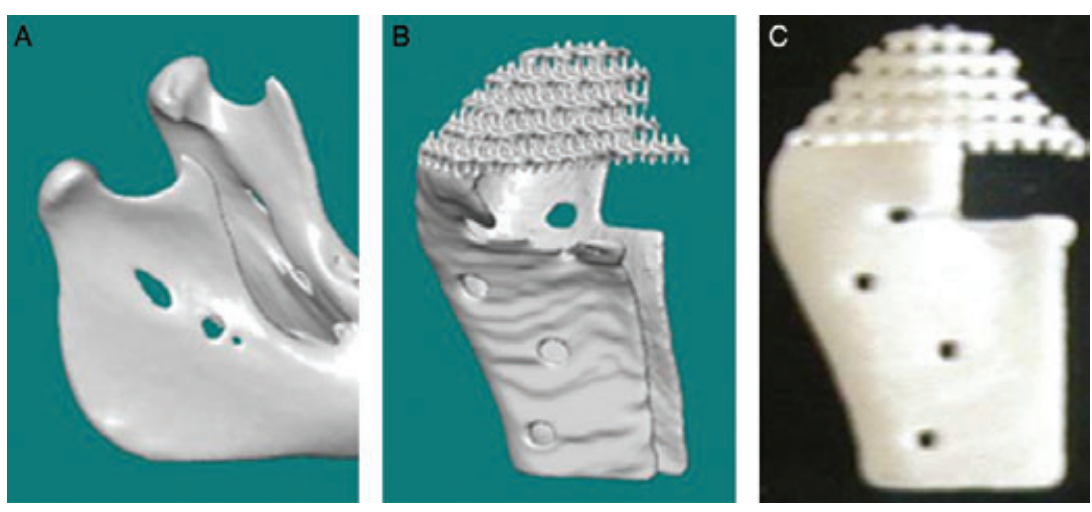


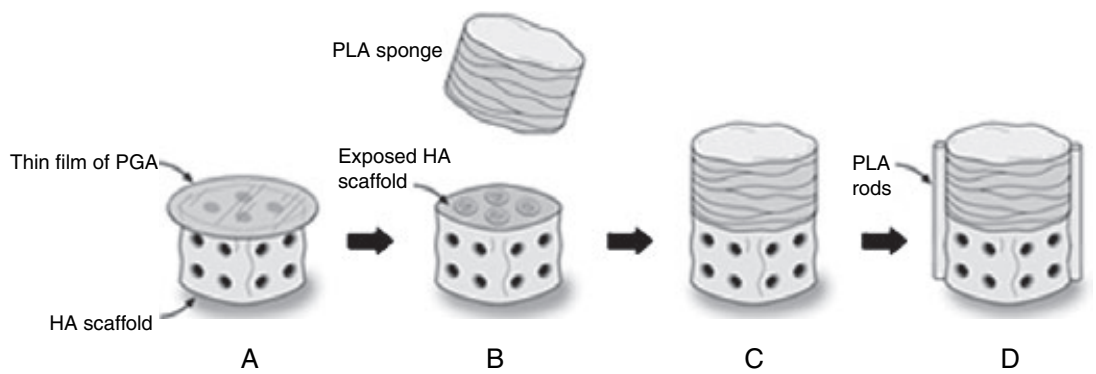

Fig. 2. Poly-L-lactic acid (PLA) was used to join the polymer and ceramic phases of the composite scaffold. One face of the ceramic was coated with a thin film of poly-gamma-glutamic acid (PGA) (A). The film was removed from the circumference and $10 \mu$ l of PLA (7.5\% in methylene chloride) was applied (B). The polymer sponge was pressed onto the ceramic scaffold, allowing the solubilized PLA to serve as adhesive (C). PLA (25\% in methylene chloride) struts were extruded on two opposite sides of the scaffold to further stabilize the composite (D).

$10^{6}$ cells in $20 \mu$ l were pipetted into the ceramic phase of the composite scaffold and the scaffold was immediately placed onto a $20 \mu \mathrm{l}$ drop of $100 \mathrm{U} / \mathrm{ml}$ bovine plamsa derived thrombin (Sigma). Fibrinogen gelation occurred quickly upon contact with the thrombin. Chondrocytes were suspended in $\mathrm{CM}$ and $10^{6}$ cells in $20 \mu$ l were pipetted into the polymer sponge phase and allowed to adhere for $1 \mathrm{~h}$ in a $37^{\circ}$ incubator. The scaffolds were immediately implanted subcutaneously into immunocompromised mice (N:NIH-bg-nu-xid; Charles River, Wilmington, MA, USA). Animals were anesthetized with intra-mesenteric injections of kentamine/ xylazine (50 and $5 \mu \mathrm{g} / \mathrm{g}$, respectively) in saline. Dorsal subcutaneous pockets were created using blunt dissection and the surgical sites were closed with wound clips.

Mice were killed after 4 weeks. The harvested implants were fixed using Z-Fix (Anatech, Battle Creek, MI, USA) and then demineralized using RDO (APEX Engineering Prodcuts Corp., Plainfield, IL, USA), which also removed the HA phase of the scaffold (24). The specimens were then embedded in paraffin, sectioned at $7 \mu \mathrm{m}$, and stained with either hematoxylin and eosin (H\&E) or safranin $\mathrm{O}$ and fast green. The safranin $\mathrm{O}$ stained glycosaminoglycans (GAGs) red and the fast green stained collagenous tissues brown.

\section{Results}

The final manufactured scaffolds matched the IBDs. This was true of both the biomimetic design (Fig. 1) and the simple cylindrical geometry design used for in vivo testing (Fig. 3 ). In the latter composite scaffold, the polymer sponge consisted of $50-100 \mu \mathrm{m}$ wide

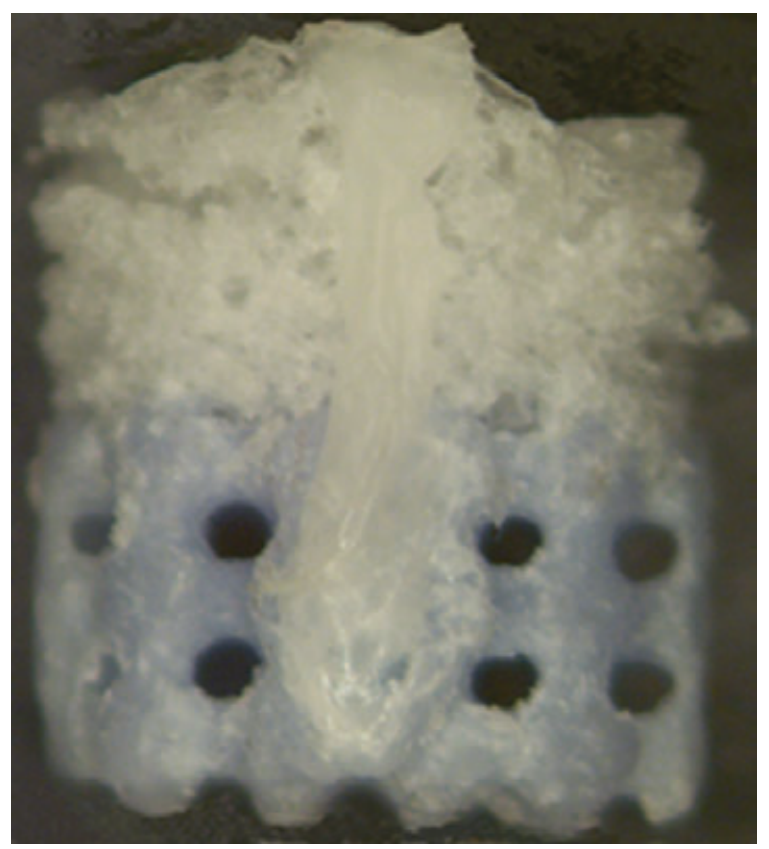

Fig. 3. The assembled composite: the upper polymer phase (white) and the lower ceramic phase (blue) are transversed by the two PLA struts, one of which is visible on the front of the construct.

interconnected pores. The PLA rods connecting the phases were in intimate contact with both the PLA and HA phases and the integrity of the composite scaffold was sufficient to withstand surgical manipulation and subsequent implantation.

The biphasic scaffolds were seeded with appropriate progenitor cells and implanted in vivo for 4 weeks. Demineralization of the implants allowed paraffin sectioning of the scaffold by removing the ceramic portion of the scaffold. In histological sections, areas that were formerly occupied by HA appear empty (Fig. 4, white areas). The upper, polymeric sponge phase of the scaffold appears rounded and stained positively with safranin $O$. This staining revealed the 

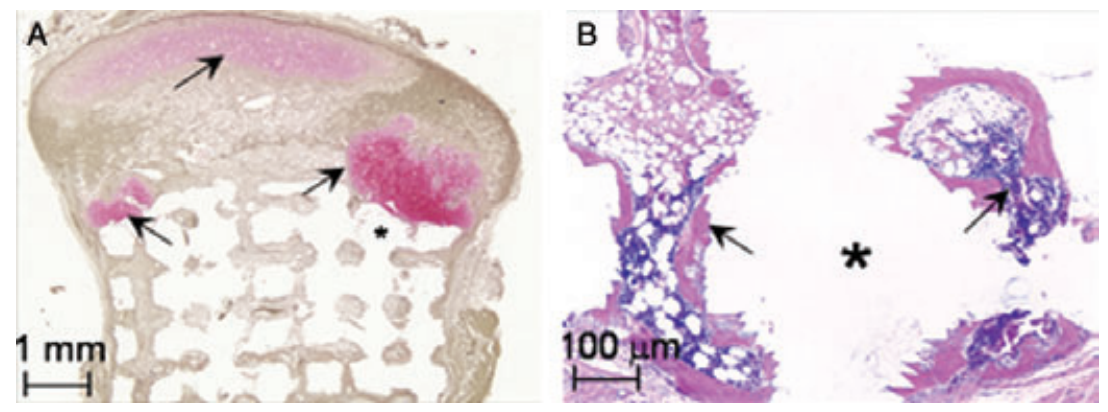

Fig. 4. Scaffolds were demineralized prior to sectioning, resulting in empty areas (marked with *) that were previously occupied by HA. Safranin $\mathrm{O}$ and fast green staining showed a large area of pink-stained cartilage (arrow) in the polymer sponge, in contact with the greenbrown-stained bone that formed in the ceramic phase (A). Small pockets of cartilage were also observed within the pores of the ceramic phase of the scaffold (A, arrow). Hematoxylin and eosin staining of the ceramic phase showed the formation of bone (B, arrow) with marrow space within the pores of the HA.

presence of GAGs in the PLA sponge phase, indicating chondrocyte synthesis of cartilage matrix (Fig. 4A). Apical regions of the polymer sponge consistently stained with safranin O. Small pockets of cartilage were also observed invading the pores of the ceramic phase (Fig. 4A, arrow in the lower region).

The ceramic region of the scaffold supported the generation of morphologically normal bone. Within the pores of the HA, bone with marrow space was observed via $H \& E$ staining (Fig. 4B). Other types of tissue including blood vessels, fibrous tissue, and fat were also observed in the HA phase of the scaffold. Taken together, these data demonstrate the development of a bone-cartilage interface on the designed, biphasic scaffolds.

\section{Discussion}

In this study, we have demonstrated the potential for combining IBD, SFF fabrication, and appropriate biological factors to tissue engineering a bone-cartilage interface that may be adapted for use in TMJ replacement. We first demonstrated the potential for this approach to create biomimetic scaffolds to replace and regenerate the joint. Our results demonstrate how these methods can be used to manufacture biphasic polymer/ceramic scaffolds that support the concurrent formation of bone and cartilage in discrete phases of the assembled scaffold. The polymeric phase of the scaffolds supported the formation of cartilage by the implanted chondrocytes, while the ceramic phase supported the formation of bone by the implanted BMP-7-transduced fibroblasts. The SFF designed channels within the ceramic phase-guided vascularization, a process that is critical to produce a biologically functional tissue. These scaffolds also supported the growth of fat and stroma, demonstrating their potential to fully mimic native skeletal tissue. Taken together, SFF-manufactured biphasic scaffolds differentially seeded with osteo- and chondro-progenitors can generate osteochondral tissue resembling native tissue, including vascularized subchondral bone and an interface tissue between bone and articular cartilage. The design and manufacturing methods presented here can be used to created biphasic scaffolds with biomimetic geometry, which can then be combined with differential seeding of progenitor cells to regenerate a joint. We have demonstrated the growth of bone and cartilage on our composite scaffolds, but the design and composition of the scaffolds may be easily modified to satisfy the mechanical requirements of the TMJ (18).

The IBD/SFF approach used here is advantageous for several reasons. As we have shown, it allows the manufacture of scaffolds to fit patient-specific injuries and match articular surface geometry using image data (19). The biphasic components can be used to differentially regulate cell differentiation and growth, promoting the regeneration of bone and vasculature in the ceramic component while maintaining the growth of cartilage in the polymeric component. Each phase may be differentially seeded with cells or loaded with biofactors. Additionally, biphasic SFF scaffolds may be designed to carry functional loads (32). Compared with the structures tested here, scaffolds designed for TMJ regeneration will likely be exposed to larger mechanical forces. However, because IBD/SFF allows great 
flexibility in scaffold design, modifications will allow the creation of scaffolds with increased ability to bear physiologic loads.

The combined use of gene therapy and SFF biphasic scaffolds represents a new strategy for the repair of human osteochondral defects and for joint replacement. The ex vivo gene therapy strategy employed here allows introduction of cells to trigger tissue formation. This approach may be advantageous for treating human defects in which disease or therapeutic irradiation have depleted progenitor cell populations or in which large joints must be reconstructured (33-36). In this study, we have demonstrated that implantation of our cell-containing scaffolds led to growth of skeletal tissues in a non-orthotopic (subcutaneous) site, in which a similar lack of progenitor cells exists. Bone formation was induced by the presence of non-osseous progenitor cells transduced with a BMP-7 adenoviral construct. This gene therapy approach provides for bone formation from cell populations that are easily harvested and expanded compared with osteoblasts or bone marrow stromal cells $(30,31)$.

While results of this study suggest that SFF-fabricated biphasic scaffolds may be useful in engineering osteochondral tissues, some improvements may be required. Tissue was not entirely confined to the area in which it was intended, specifically pockets of cartilage were observed in the ceramic phase. Therefore, although the biphasic scaffolds were designed to control cell seeding, greater control over the spatial distribution of regenerate tissue is desired. Altering the interface between geometry may improve cell seeding and decrease the interaction between the progenitor cells in the two scaffold phases. Additionally, an advanced understanding of how the scaffold internal architecture regulates interface tissue formation may be used to enhance formation of a uniform mineralized tissue interface between bone and cartilage similar to the tidemark.

In conclusion, IBD and SFF-manufactured HA and PLA biphasic composite scaffolds, coupled with differential cell seeding and gene therapy, generated osteochondral tissue, including cartilage, vascularized bone, and an organized bone-cartilage interface. In an ectopic site, the tissue formation was not highly uniform, but these results suggest that these methods may be effective in regenerating osteochondral tissue in situ. IBD and SFF fabrication can be used to manufacture biphasic composites that are capable of carrying functional loads upon implantation, replicating articular surface geometry and promoting integration with host tissues. We hope to combine these biological results with the biomimetic scaffold designs presented here and investigate the potential of this approach in regenerating a mechanically and biologically functional joint in an orthotopic site.

Acknowledgements: Support from NIH R01 DE 13608. The authors wish to thank Dr Suman Das and Mr Brock Partee for fabrication of the scaffold shown in Fig. 1.

\section{References}

1. Perrott DH, Umeda H, Kaban LB. Costochondral graft construction/reconstruction of the ramus/condyle unit: long-term followup. Int J Oral Maxillofac Surg 1994;23:321-8.

2. Raustia A, Pernu H, Pyhtinen J, Oikarinen K. Clinical and computed tomographic findings in costochondral grafts replacing the mandibular condyle. J Oral Maxillofac Surg 1996;54:1393-1400.

3. Mercuri LG. Alloplastic temporomandibular joint reconstruction. Oral Surg Oral Med Oral Pathol Oral Radiol Endod 1998;85:631-7.

4. Rubin JP, Yaremchuk MJ. Complications and toxicities of implantable biomaterials used in facial reconstructive and aesthetic surgery: a comprehensive review of the literature. Plast Reconstr Surg 1997;100:1336-53.

5. Feinberg SE, Hollister SJ, Halloran JW, Chu TM, Krebsbach PH. Image-based biomimetic approach to reconstruction of the temporomandibular joint. Cells Tissues Organs 2001;169:309-21.

6. Vunjak-Novakovic G, Martin I, Obradovic B, Treppo S, Grodzinsky AJ, Langer R et al. Bioreactor cultivation conditions modulate the composition and mechanical properties of tissue-engineered cartilage. J Orthop Res 1999;17:130-8.

7. Dounchis JS, Bae WC, Chen AC, Sah RL, Coutts RD, Amiel D. Cartilage repair with autogenic perichondrium cell and polylactic acid grafts. Clin Orthop 2000;377:248-64.

8. Alsberg E, Anderson K, Albeiruti A, Rowley J, Mooney D. Engineering growing tissues. Proc Natl Acad Sci U S A 2002;99:12025-30.

9. Martinek V, Ueblacker $P$, Imhoff $A B$. Current concepts of gene therapy and cartilage repair. J Bone Joint Surg Br 2003;85:782-8.

10. Holland TA, Mikos AG. Advances in drug delivery for articular cartilage. J Control Release 2003;86:1-14.

11. Brittberg M, Tallheden T, Sjogren-Jansson B, Lindahl A, Peterson L. Autologous chondrocytes used for articular cartilage repair: an update. Clin Orthop 2001;391:S161-70.

12. Solchaga LA, Goldberg VM, Caplan AI. Cartilage regeneration using principles of tissue engineering. Clin Orthop 2001;391:S161-70.

13. Palmer G, Pascher A, Gouze E, Gouze JN, Betz O, Spector M et al. Development of gene-based therapies for cartilage repair. Crit Rev Eukaryot Gene Expr 2002;12:259-73.

14. Kreklau B, Sittinger M, Mensing MB, Voigt C, Berger G, Burmester GR et al. Tissue engineering of biphasic joint cartilage transplants. Biomaterials 1999;20:1743-9.

15. Schaefer D, Martin I, Jundt G, Seidel J, Heberer M, Grodzinsky A et al. Tissue-engineered composites for the repair of large osteochondral defects. Arthritis Rheum 2002;46:2524-34. 
16. Gao J, Dennis J, Solchaga L, Awadallah A, Goldberg V, Caplan A. Tissue-engineered fabrication of an osteochondral composite graft using rat bone marrow-derived mesenchymal stem cells. Tissue Eng 2001;7:363-71.

17. Hutmacher D. Scaffolds in tissue engineering bone and cartilage. Biomaterials 2000;21:2529-43.

18. Hollister S, Maddox R, Taboas J. Optimal design and fabrication of scaffolds to mimic tissue properties and satisfy biological constraints. Biomaterials 2002;23:4095-103.

19. Hollister SJ, Levy RA, Chu TM, Halloran JW, Feinberg SE. An image-based approach for designing and manufacturing craniofacial scaffolds. Int J Oral Maxillofac Surg 2000;29:67-71.

20. Lin CY, Lin C, Hollister SJ. A new approach for designing biodegradable bone tissue augmentation devices by using degradation topology optimization. 8th World Multiconference on Systemics, Cybernetics and Informatics, Orlando, FL, USA, 2004.

21. Lin CY, Hsiao CC, Chen PQ, Hollister SJ. Interbody fusion cage design using integrated global layout and local microstructure topology optimization. Spine 2004;15:1747-54.

22. Schek R, Taboas JM, Segvich S, Hollister SJ, Krebsbach PH. Engineered osteochondral grafts on biphasic composite solid free form fabricated scaffolds. Tissue Eng 2004;10:1376-85.

23. Sherwood JK, Riley SL, Palazzolo R, Brown SC, Monkhouse DC, Coates $\mathrm{M}$ et al. A three-dimensional osteochondral composite scaffold for articular cartilage repair. Biomaterials 2002;23:473951.

24. Taboas JM, Maddox RD, Krebsbach PH, Hollister SJ. Indirect solid free form fabrication of local and global porous, biomimetic and composite 3D polymer-ceramic scaffolds. Biomaterials 2003;24:181-94.

25. Chu TM, Hollister SJ, Halloran JW, Feinberg SE, Orton DG. Manufacturing and characterization of 3-d hydroxyapatite bone tissue engineering scaffolds. Ann N Y Acad Sci 2002;961:114-7.

26. Rutherford RB, TrailSmith MD, Ryan ME, Charette MF. Synergistic effects of dexamethasone on platelet-derived growth factor mitogenesis in vitro. Arch Oral Biol 1992;37:139-45.

27. Franceschi RT, Wang D, Krebsbach PH, Rutherford RB. Gene therapy for bone formation: in vitro and in vivo osteogenic activity of an adenovirus expressing BMP7. J Cell Biochem 2000;78:476-86.

28. Gazit D, Turgeman G, Kelley P, Wang E, Jalenak M, Zilberman Y et al. Engineered pluripotent mesenchymal cells integrate and differentiate in regenerating bone: a novel cell-mediated gene therapy. J Gene Med 1999;1:121-33.

29. Lieberman JR, Le LQ, Wu L, Finerman GA, Berk A, Witte ON et al. Regional gene therapy with a BMP-2-producing murine stromal cell line induces heterotopic and orthotopic bone formation in rodents. J Orthop Res 1998;16:330-9.

30. Rutherford RB, Moalli M, Franceschi RT, Wang D, Gu K, Krebsbach $\mathrm{PH}$. Bone morphogenetic protein-transduced human fibroblasts convert to osteoblasts and form bone in vivo. Tissue Eng 2002;8:441-52.

31. Krebsbach PH, Gu K, Franceschi RT, Rutherford RB. Gene therapy-directed osteogenesis: BMP-7-transduced human fibroblasts form bone in vivo. Hum Gene Ther 2000;11:1201-10.

32. Saito E, Flanagan CL, Taboas JM, Kohn DH, Krebsbach PH, Hollister SJ. Mechanical and structural properties of designed PLLA, PLGA, and PGA scaffolds made by indirect solid free form fabrication. Presented at the Society for Biomaterials 29th Annual Meeting; Reno, NV, USA, 2003.

33. Hernigou P, Beaujean F, Lambotte JC. Decrease in the mesenchymal stem-cell pool in the proximal femur in corticosteroid-induced osteonecrosis. J Bone Joint Surg $\mathrm{Br}$ 1999;81:349-55.

34. Murphy JM, Dixon K, Beck S, Fabian D, Feldman A, Barry F. Reduced chondrogenic and adipogenic activity of mesenchymal stem cells from patients with advanced osteoarthritis. Arthritis Rheum 2002;46:704-13.

35. Wall E, Von Stein D. Juvenile osteochondritis dissecans. Orthop Clin North Am 2003;34:341-53.

36. Nussenbaum B, Rutherford RB, Teknos TN, Dornfeld KJ, Krebsbach $\mathrm{PH}$. Ex vivo gene therapy for skeletal regeneration in cranial defects compromised by preoperative radiation. Hum Gene Ther 2003;14:1107-15. 